\title{
Myasthenia gravis in pregnancy: a rare association with an unpredictable evolution - three cases presentation
}

\author{
Benjilany Aboubakr, Kouach Jaouad
}

Department of Obstetrics and Gynecology, Military Hospital of Instruction Mohamed V, Rabat, Morocco

\begin{abstract}
Myasthenia gravis is a neuro-immunological disease due to the blockage of motor plate post-synaptic receptors by antiacetylcholine receptors antibodies, causing excessive fatigability of skeletal striated muscles. Thus, vital prognosis is engaged by swallowing disorders and respiratory distress related to pharyngeal striated and intercostal muscles damage.

Myasthenia evolves by flare-ups, with two peaks of prevalence: first one, between 20 and 30 years-old with femal predominance. Then after 40 years-old, sex ratio evens out. Therefore, association of myasthenia and pregnancy is not exceptional, hence the interest in knowing particularities of these pregnancies, to ensure optimal monitoring for both mother and child. Indeed, mother's risk is myasthenia decompensation, while child's risk is neonatal myasthenia gravis. We report three myasthenia and pregnancy cases, from prenatal period to pueripartum, then we discuss in literature light, myasthenia gravis bidirectional influence on pregnancy, as well as impact of anti-myasthenic treatments on pregnancy.
\end{abstract}

Keywords: myasthenia gravis, neuromuscular disease, autoimmune disorder, pregnancy

\section{INTRODUCTION}

Myasthenia gravis is a chronic autoimmune neurological disease, linked to a blockage of transmission at neuromuscular motor plate post-synaptic receptors by antiacetylcholine nicotinic receptors antibodies, which are detectable in approximately $80 \%$ of generalized myasthenias. For remaining 20\%, anti-MuSK (anti tyrosine kinase receptor) antibodies are found in 40-70\% [1]. Prevalence is $0,25-2$ per 100,000 . There are two peaks of prevalence; between 20 and 30 years-old with femal predominance (sex ratio 2/1) [2,3], then after 40 years-old when sex ratio is equalized [4].

Therefore, association of myasthenia and pregnancy is not exceptional. It is important to know particularities of these pregnancies in order to ensure optimal management of both mother and child.

\section{CASES PRESENTATION}

\section{Case 1}

Mrs. Z.H. is 28 years-old, diagnosed 5 years ago with myasthenia gravis (in 2016), thymectomized 4 years ago (in 2017), put under pyridostigmine (Mestinon $60 \mathrm{mg}$ ) 4 tablets/day, azathioprine (Imurel $50 \mathrm{mg}$ ) 3 tablets/day, and prednisone (Cortancyl $5 \mathrm{mg}$ ) 2 tablets/day. Evolution is marked by stabilization with no myasthenic crisis occurence. 4 gestities, 3 parities (vaginal delivery). Current pregnancy is estimated at 38 amenorrhea weeks (AW), followed-up in our department, where she benefited from several prenatal consultations, and 3 obstetrical ultrasound scans, these investigations did not reveal any myasthenia gravis decompensation during pregnancy, nor any fetal immobility syndrome, fetal malformations or other associated 
signs (polyhydramnios, muscles hypertrophy). Prenatal check-up objectified Iron deficiency anemia put under Iron at curative dose, and gestational diabetes put under hygieno-dietary measures, with a satisfying glycemic balance. Parturient was summoned for prophylactic caesarean delivery management after obstetrical staff decision, having presented the same day a non-complicated membranes premature rupture (MPR). Caesarean section allowed female newborn extraction, APGAR score 10/10, $2850 \mathrm{~g}$ birth weight, received by pediatrician, which examination detected a slight axial hypotonia without respiratory struggle signs or sucking disorders. Breastfeeding was allowed subject to muscarinic hyperstimulation signs appearance, an infection check-up consisting on hemogram, C-reactive protein and trans-fontanel ultrasound scan were recommended to eliminate maternal-fetal infection in MPR context, came back negative. She did not show signs of decompensation, newborn did not show objective signs of neonatal myasthenia gravis.

\section{Case 2}

Mrs. F.S. is 30 years-old, diagnosed in 2003 with myasthenia gravis undergoing treatment: ambenonium chloride (Mytelase $10 \mathrm{mg}$ ) 4 tablets/day, azathioprine (Imurel $50 \mathrm{mg}$ ) 3 tablets/day and prednisone (Cortancyl $5 \mathrm{mg}$ ) 2 tablets/day. Patient did not undergo thymectomy. Evolution is marked by symptomatology stabilization with no myasthenia crisis occurence, hence treatment discontinuation 6 months before conception. 2 gestities with an early spontaneous abortion 2 years ago. Current pregnancy is estimated at $24 \mathrm{AW}$, followed-up in our department, where she benefited from 2 prenatal consultations, and 2 obstetrical ultrasound scans ( 8 and $22 \mathrm{AW}$ ), these investigations did not reveal any myasthenia decompensation during pregnancy, nor any myasthenia fetal impact. prenatal check-up was satisfying. Parturient was admitted for management of an uncomplicated membranes premature rupture. Clinical examination found an apyretic patient in a good general condition. Obstetrically, she contracted with a modified cervix on vaginal touch. Ultrasound scan confirmed an evolving pregnancy, biometrics corresponded to 24 AW with no amniotic fluid found. Patient was hospitalized, was put under antibio- prophylaxis, an infectious assessment (hemogram and C-reactive protein) was carried out and came back negative afterwards. 2 hours later, patient was fully dilated with vaginal delivery of a female newborn weighing 800g, APGAR 4-6 then 8 at 10 min, without detectable clinical abnormalities, died at first life hour from major neonatal respiratory distress. Patient did not show myasthenic decompensation signs in pueripartum.

\section{Case 3}

Mrs. O.E. is 35 years-old, 3 gestities, 2 parities (vaginal delivery), diagnosed with myasthenia gravis since 13 years, undergoing treatment: pyridostigmine (Mestinon $60 \mathrm{mg}$ ) 6 tablets/day and azathioprine (Imurel $50 \mathrm{mg}$ ) 3 tablets/day. She did not benefit from a thymectomy. Evolution is marked by symptomatology stabilization with no myasthenic crisis occurrence. Current pregnancy was allowed 6 months after stopping immunosuppressive treatment, estimated at $37 \mathrm{AW}$, followed-up in our department, where she benefited from 3 prenatal consultations, and 3 obstetrical ultrasound scans. At $21 \mathrm{AW}$, she presented a heaviness associated to lower limbs abnormal fatigability, without subjective or sphincter sensory disorders evolving in asthenia context, apyrexia and general state conservation. General examination found an eupneic patient, hemodynamically stable. Neurological examination showed no abnormalities but a slight pelvic girdle and lower limbs proximal musculature motor deficit during Barré and Mingazzini maneuvers. Diagnosis of a myasthenic decompensation was retained; pyridostigmine (Mestinon $60 \mathrm{mg}$ ) was reintroduced at 4 tablets/day, with satisfying clinical recuperation. Fetal ultrasound scan did not reveal any myasthenia impact signs. Moreover, the rest of prenatal check-up was normal. Caesarean delivery was performed at $37 \mathrm{AW}$ for an obstetrical indication (uncomplicated membranes premature rupture more than 24 hours with unfavorable Bishop score), allowing male newborn extraction, APGAR score $10 / 10$ at 1,5 and 10 life minutes, birth weight at 3,550 g, received by pediatrician, he presented a slight respiratory distress improving under oxygen, hence his prophylactic hospitalization in neonatology. Artificial breastfeeding was preferred. Patient did not show signs of myasthenic decompensation in puerperium. 


\section{DISCUSSION}

Myasthenia gravis is manifested by strial musculature abnormal fluctuating fatigability, leading to ptosis, diplopia, chewing, swallowing and speaking difficulties, and scapular-pelvic belts weakness. Respiratory distress risks and miscarriage may compromise patient's vital prognosis. An association with thymus damage (hyperplasia, thymoma) should be sought. Particularities of these pregnancies should be known to ensure optimal monitoring for both mother and child. Indeed, mother's risk is myasthenia decompensation, moreover, many medications are contraindicated [2,5]. Child major risk is neonatal myasthenia, which may require intensive care monitoring [2].

\section{Influence of pregnancy on myasthenia gravis}

Pregnancy should be planned during stable myasthenia gravis period. Several authors believe that the evolution of myasthenia gravis during pregnancy is not predictable [2]. In a French study, there was no improvement, but 5 worsening cases out of 13 pregnancies [6]. Pregnancy is one of myasthenia gravis revealers factors [7]. Relapses seem occurring more frequently in non thymectomized patients, but this treatment efficacy has not been proven in controlled studies [4,8]. Relapses also appear occurring more frequently when time between disease discovery and pregnancy onset is shorter [9].

Some medications such as aminoglycosids, intravenous magnesium and some calcium channel blockers, which are frequently used during pregnancy, are formally contraindicated. For our patients, all medications have respected contraindicated drugs list. Anticholinesterase medications should not be interrupted especially during labor. A myasthenic flare-up can be treated by immunoglobulins or plasmapheresis, including during pregnancy [10]. Postpartum period can also be a decompensating factor of myasthenia gravis $[6,9]$.

\section{Influence of myasthenia gravis on fetus}

Maternal antiacetylcholine receptor antibodies have some affinity for fetal acetylcholine receptor isoforms [10]. Some authors have described fetal immobilism and arthrogryposis cases related to myasthenia gravis [11-12]. This was not our patients' case. Polyhydramnios is frequent and even led to myasthenia diagnosis [13]. Carr et al. described a myasthenic patient case, who had two died newborns from fetal malformations and who had a third child with neonatal myasthenia but without malformation, after corticosteroid and plasmapheresis treatment [11]. Myasthenia is not associated with more prematurity, hypotrophy or caesarean section [14].

\section{Influence of myasthenia gravis on childbirth}

Uterine muscle being a sleek muscle, function is not disturbed in myasthenia. Duration of labor is therefore not modified. Delivery is not impacted $[7,15]$. However, prolonged and tiring labor can cause myasthenia gravis decompensation. Epidural and spinal anesthesia are not a problem and should be performed early [7]. It should be remembered that some drugs used during anesthesia (curare) are contraindicated in myasthenia gravis $[7,15]$.

\section{Influence of myasthenia gravis on newborn and breastfeeding}

Neonatal myasthenia gravis is found in 10 to $20 \%$ of cases $[6,16]$. Developed symptoms in first 24 hours are sucking and swallowing difficulties, weak cries or respiratory distress [16]. It's due to antibodies transplacental passage [15]. The reason why some children develop neonatal myasthenia gravis and others do not is unclear. Gardnerova et al. described that the ratio of maternal antibody subtypes (fetal and maternal acetylcholine receptor antibodies) is predictive of neonatal myasthenia gravis [17]. Eymard et al. showed that there is a link between levels of maternal acetylcholine receptor antibody and occurrence of neonatal myasthenia gravis [18]. However, other studies did not find correlation between antibody title and neonatal status $[9,19,20]$. Disease age was inversely correlated with neonatal myasthenia gravis occurrence [21], and thymectomized mothers have fewer children with neonatal myasthenia gravis than others [8,21]. Another study found no neonatal myasthenia gravis predictive factor [22]. $80 \%$ of myasthenic mothers' newborns have circulating antibodies even though they have no neurological symptoms [18]. Neostigmine is usually sufficient, combined with intensive care management in severe form cases. Several neonatal myasthenia cas- 
es in mothers with positive anti-MuSK antibodies are described [23]. Literature reports a more severe and prolonged neonatal myasthenia gravis forms with anti-MuSK antibodies [24].

It's known that anticholinesterase drugs pass into breast milk and can have muscarinic-like side effects in children [2,24]. Breastfeeding is controversial; some authors believe that a patient in remission with low antibody levels and without dangerous drugs can breastfeed without risk, and artificial breastfeeding should be preferred in other cases $[2,4]$.

\section{Influence of anti-myasthenic treatment on pregnancy}

Myasthenic patients may be treated with one or more of these treatments: anticholinesterase drugs, immunoglobulins, corticosteroids, immunosuppressants and plasmapheresis. It is also important to preserve the best possible control and therefore myasthenia gravis stability, and to avoid teratogenic risks as much as possible. An abrupt treatment cessation in view of pregnancy could provoke a decompensation. A case of newborn's muscles hypertrophy has been described whose mother received very high neostigmine doses [25], pyridostigmine also has been implicated in a microcephaly case [26]. Corticosteroid therapy is generally continued during pregnancy. Among immunosuppressive drugs, azathioprine, used as a first-line drug does not seem entailing any increased teratogenic risk [15]. On the other hand, mycophenolate mofetil is implicated in occurrence of children facial and cardiac malformations. There are a very few data about cyclophosphamid, cyclosporin, and tacrolimus effects in myasthenic patients pregnancies [15]. Our patients used the above mentioned drugs without any teratogenic effects.

\section{CONCLUSIONS}

Management of these patients must be rigorous and multidisciplinary because of maternal myasthenic decompensation risk and neonatal myasthenia gravis risk. Systematic ultrasound scans and active movements monitoring are sufficient. A systematic ultrasound scan at third trimester is desirable in order to eliminate fetal immobility syndrome. In all cases, children should be monitored during pueriperium. Stable patients during pregnancy should not routinely be admitted in intensive care, but only a clinical surveillance. However, it is reasonable that patients with complications during pregnancy or caesarean section should be monitored in intensive care during pueriperium.

Conflict of interest: none declared Financial support: none declared

\section{REFERENCES}

1. Gajdos P. Seronegative myasthenia gravis. Rev Neurol. 2004;160:159-62.

2. Mitchell $P J$, Rebbington M. Myasthenia gravis and pregnancy. Obstet Gynecol. 1992;80:178-81.

3. Giwa-Osagie OF, Newton JR, Larcher V. Obstetric performance of patients with myasthenia gravis. Int J Gynaecol Obstet. 1981;19:267-70

4. Vincent A, Palace J, Hilton-Jones D. Myasthenia Gravis. Lancet. 2001;357:2122-8.

5. Camus M, Clouard C. Myasthénie et grossesse. À propos de 8 cas. J Gynecol Obstet Biol Reprod. 1989;18:905,01.

6. Picone $\mathrm{O}$, Audibert F, Gajdos P, et al. Myasthénie et grossesse: À propos de 13 grossesses. J Gynecol Obstet Biol Reprod. 2003;32:654-9.

7. Almeida C, Coutinho E, Moreira D, et al. Myasthenia gravis and pregnancy: anaesthetic management a series of cases. Eur $\mathrm{J}$ Anaesthesiol. 2010;27:985-90.

8. Roth TC, Raths J, Carboni G, et al. Effect of pregnancy and birth on the course of myasthenia gravis before or after transsternal radical thymectomy. Eur J Cardiothorac Surg. 2006;29:231-5.

9. Hoff JM, Daltveit AK, Gilhus NE. Myasthenia gravis in pregnancy and birth: identifying risk factors, optimising care. Eur J Neurol. 2007;14:38-43.

10. Vernet Der Garabedian B, Lacokova M, Eymard B, et al. Association of neonatal myasthenia gravis with antibodies against the fetal acetylcholine receptor. J Clin Invest. 1994;94:555-9.

11. Carr SR, Gildchrist JM, Abuelo DN, et al. Treatment of antenatal myasthenia gravis. Obstet Gynecol. 1991;78:485-9.

12. Polizzi A, Husson SM, Vincent A. Teratogen update: maternal myasthenia gravis as a cause of congenital arthropryposis. Teratology. 2000;62:332-41.

13. Verspyck E, Mandelbrot L, Dommergues $M$, et al. Myasthenia gravis with polyhydramnios in the fetus of an asymptomatic mother. Prenat Diagn. 1993;13:539-42.

14. Wen JC, Liu TC, Chen YH, et al. No increased risk of adverse pregnancy outcomes for women with myasthenia gravis: a nationwide population-based study. Eur J Neurol. 2009;16:889-94.

15. Ramirez C, de Seze J, Delrieu O, et al. Myasthenia gravis and pregnancy: clinical course and management of delivery and the post-partum phase. Rev Neurol. 2006;162:330-8.

16. Lucot JP, Dufour P, Vinatier D, et al. Myasthénie et grossesse. J Gynecol Obstet Biol Reprod. 1996;25:179-85.

17. Gardnerova M, Eymard B, Morel E, et al. The fetal/adult acetylcholine receptor antibody ratio in mothers with myasthenia gravis as a marker for transfer of the disease to the newborn. Neurology. 1997;48:50-4. 
18. Eymard B, Morel E, Dulac O, et al. Myasthénie et grossesse: étude clinique et immunologique de 42 cas (21 myasthénies néonatales). Rev Neurol. 1989;145:696-701.

19. Batocchi AP, Majolini L, Evoli, A et al. Course and treatment of myasthenia gravis during pregnancy. Neurology. 1999;52:447-52.

20. Cheng I, Lin CH, Lin Ml, et al. Outcome of myasthenia gravis mothers and their infants. Acta Paediatr Taiwan. 2007;48:141-5.

21. Djelmis J, Sostarko M, Mayer D, et al. Myasthenia gravis in pregnancy: report of 69 cases. Eur J Obstet Gynecol. 2002; 104:21-5.

22. Gveric-Ahmetasevic S, Colić A, Elvedji-Gasparović V, et al. Can neonatal myasthenia gravis be predicted ? J Perinat Med. 2008;36:503-6.
23. O'Caroll P, Bertorini TE, Jacob G, et al. Transient neonatal myasthenia gravis in a baby born to a mother with new onset anti-MuSK mediated myasthenia gravis. J Clin Neuromuscul Dis. 2009;11:69-71.

24. Evoli A. Acquired myasthenia gravis in childhood. Curr Opin Neurol. 2010;23:536-40.

25. Cooker J, Thomson RM. Multiple smooth hypertrophies in a new born infant. Arch Dis Child. 1966;41:514-8.

26. Niesen CE, Shah NS. Pyridostigmine induced microcephaly. Neurology. 2000;54:1873-4. 